\title{
COMPARISON OF BIOCOMPATIBILITY AND BIODEGRADABILITY OF POLY(LACTIC-CO-GLYCOLIC ACID) (PLGA) COMBINED WITH AUTOLOGOUS FIBRIN VERSUS PLGA FOR INTRA-ARTICULAR SCREW FIXATION; AN IN- VIVO STUDY WITH NEW ZEALAND WHITE RABBITS- THE MICRORADIOGRAPH OUTCOME
}

Theenesh Balakrishnan ${ }^{1}$, Ahmad Hafiz Zulkifli ${ }^{1}$, Munirah Sha'ban ${ }^{2}$, Nurul Hafiza Mohd Jan $^{1}$, Mohd Zulfadzli Ibrahim ${ }^{1}$, Noorhidayah Md Nazir ${ }^{2}$

${ }^{1}$ Department of Orthopaedics, Kulliyyah of Medicine, International Islamic University Malaysia, Pahang, Malaysia, ${ }^{2}$ Department of Biomedical Science, Kulliyyah of Allied Health Sciences, International Islamic University Malaysia, Pahang, Malaysia.

Presenter: Dr Theenesh, tneshseven@gmail.com

Introduction: The great potential of biodegradable polymers in orthopaedic surgery is gradually being recognized. PLGA is one of the common polymers used. However, long term outcomes, with regards to PLGA, are still not well documented. Hence, we attempted to study the outcome of PLGA and also its combination with fibrin.

Materials and method: Objectives : 1) To compare biocompatibility and biodegradability of polymer (PLGA + fibrin) with PLGA for intra-articular screw fixation 2) to study the imaging microradiograph) features. We used fabricated PLGA scaffolds in combination with autologous fibrin for an in-vivo prospective research. Total of nine New Zealand White Rabbits (NZWR) were operated and the scaffolds were placed at both medial and lateral femoral condyles of the right knee and those with fibrin at the left knee. Post implantation, evaluation was done at 6,12 and 24 weeks (three NZWR in each group). For microradiological assessment, micro CT (Skyscan 1176) was used.

Results: The combination of PLGA and fibrin has better biocompatibility, showed faster biodegradation and more quantitative integration of osseous tissues.

Conclusion: Biodegradable polymer PLGA with incorporation of fibrin resulted in superior outcome compared to usage of other current biodegradable polymers. 